\title{
Labetalol in the treatment of elderly patients with mild essential hypertension
}

\author{
CHARLES A. NUGENT, MD \\ JEFFREY M. BLEICHER, DO \\ JOHN R. PLACHETKA, PHARM D
}

Fifty-two elderly hypertensive patients with standing diastolic $(90-110 \mathrm{~mm}$ $\mathrm{Hg})$ or systolic $(\mathbf{1 6 0}-240 \mathrm{~mm} \mathrm{Hg})$ blood pressure elevations were assigned randomly to receive labetalol or placebo in a double-blind study. Baseline standing blood pressure in the two groups were similar. The goal of treatment was to reduce standing pressure to $<150 /<90 \mathrm{~mm} \mathrm{Hg}$ (or, for systolic pressure, a decrease of at least $10 \%$. If blood pressure was uncontrolled after labetalol or placebo use for four weeks, hydrochlorothiazide (HCTZ) was added. During the titration phase, goal blood pressure was achieved by all 25 patients receiving labetalol, and 20 of these 25 required $<200 \mathrm{mg}$ twice a day. No patient receiving labetalol required addition of HCTZ. By contrast, HCTZ was required by 12 of $25(48 \%)$ placebo patients, eight of whom were controlled by the end of titration. By the end of the four-week maintenance phase, 18 of $25(72 \%)$ patients receiving labetalol and 10 of $21(48 \%)$ patients receiving placebo or placebo and HCTZ had blood pressures with the target range $(P<.05)$. No patient withdrew because of drug-related adverse events. Labetalol in low dosages appears to be an effective and well-tolerated antihypertensive monotherapy in elderly patients.

Hypertension is a common disorder in the elderly population. The First National Health and Nutrition Examination Survey ${ }^{1}$ in 1984 indicated

\section{Patient selection
Patients aged 60 to 80 years who had systolic (160- \\ Patient selection
Patients aged 60 to 80 years who had systolic (160-}

that approximately 3 of 10 white persons and 4 of 10 black persons 65-74 years of age had systolic pressures $>160 \mathrm{~mm} \mathrm{Hg}$ or diastolic pressures $>90$ $\mathrm{mm} \mathrm{Hg}$.

There is no reliable evidence that elderly persons easily tolerate high blood pressure. ${ }^{2}$ In fact, the risk of cardiovascular complications from high blood pressure increases with age. ${ }^{3,4}$ However, appropriate treatment of hypertension in the elderly may significantly reduce cardiovascular morbidity and mortality..$^{5-7}$

The hemodynamic profile of the elderly hypertensive patient differs from that of the young person with high blood pressure. In general, the elderly have higher total peripheral resistance, lower blood volume, lower cardiac output, and lower plasma renin activity. ${ }^{8,9}$ Therefore, drugs that lower peripheral resistance have been proposed as being especially suitable for the elderly patient. $^{9}$

Labetalol, an alpha-1- and a nonselective betablocker, ${ }^{10,11}$ decreases blood pressure primarily by reducing peripheral resistance while having little or no effect on cardiac output. ${ }^{12,13}$ This study was designed to evaluate the efficacy and safety of labetalol therapy in a group of elderly patients with mild essential hypertension.

\section{Methods}

This double-blind, placebo-controlled titration study was conducted at two medical centers. The Human Studies Committees of the two institutions approved the study design, and all subjects gave their informed consent. 
$240 \mathrm{~mm} \mathrm{Hg}$ ) or diastolic $(90-110 \mathrm{~mm} \mathrm{Hg})$ hypertension or both were selected for the study. Patients were excluded if there was evidence of any of the following: estrogen-induced hypertension; renovascular hypertension; pheochromocytoma; primary aldosteronism; retinal exudates; hemorrhages or papilledema; cerebrovascular accident within the preceding two years; acute myocardial infarction within the previous six months; bradycardia $(<50$ beats per minute), heart block beyond first degree; uncontrolled arrhythmias; atrial fibrillation; congestive heart failure; diabetes mellitus that required treatment with insulin or oral hypoglycemic agents; history of seizure disorders; significant liver, hematologic, respiratory, renal, or neurologic disease; asthma or allergic rhinitis; past history of adverse reactions to beta-blocking drugs; current use of glucocorticoid or sympathomimetic agents, use of guanethidine or reserpine within two weeks of entering the study; history of alcohol or drug abuse; serious personality disorders or intellectual deficits; or history of accelerated or malignant hypertension.

\section{Observations}

Blood pressure was measured three times at 30 second intervals after the patient had been standing for two minutes, and the mean pressure was recorded. The pulse rate also was determined while the patient was standing. Standing blood pressure was used to guide treatment in this study. The pulse rate and the mean of three blood pressure determinations while the patients were seated also were recorded at every visit, but these results were not used in patient management.

On the initial visit, the following were obtained: history, physical examination, chest x-ray, ECG, blood chemistry values, and a complete blood count. On every subsequent visit, measurements were made of body weight, blood pressure, and pulse rate. Patients were asked how they felt at each visit, and any complaints were investigated further. Patients were instructed to take their last dose of medication 8-12 hours before each study visit. At each visit, patients were supplied with new bottles of medication and asked to return their old bottles for compliance checks. Blood chemistry studies, complete blood count, physical examination, and electrocardiography were repeated at the final visit.

\section{Placebo washout phase}

Visits were weekly in the four-week placebo washout phase. Patients who had standing blood pressures of $160-240 \mathrm{~mm} \mathrm{Hg}$ systolic or $90-109 \mathrm{~mm} \mathrm{Hg}$ diastolic or both on the last visit of this phase were

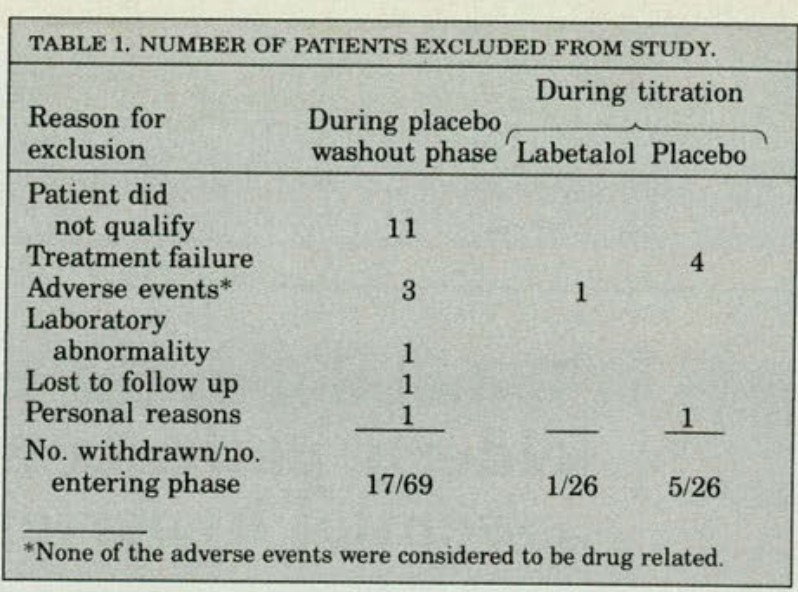

randomly assigned to treatment with either placebo or labetalol.

\section{Titration and maintenance phases}

Patients entering the titration phase were instructed to take $100 \mathrm{mg}$ twice a day of either placebo or labetalol. They returned for weekly visits, and the dose of labetalol or placebo was increased each week by $100 \mathrm{mg}$ twice daily, to a maximum of $400 \mathrm{mg}$ twice daily, until blood pressure control was achieved. Therapeutic control of blood pressure was defined as standing diastolic pressure of $<90 \mathrm{~mm} \mathrm{Hg}$ and a reduction in standing systolic pressure to $<150 \mathrm{~mm} \mathrm{Hg}$ or by at least $10 \%$ from baseline.

If control was not achieved by the fourth week with the maximum dose of labetalol or placebo, hydrochlorothiazide (HCTZ) (25 mg twice a day) was added to the regimen. If blood pressure was not controlled with this combined therapy by the fourth week of the titration phase or if intolerable side effects occurred, the patient was removed from the study. As soon as blood pressure was controlled, patients entered a four-week maintenance phase and were seen every two weeks while continuing with the effective dosage.

\section{Statistical analyses}

Differences between groups relative to change in vital sign data were compared using two sample t-test procedures. The percent of patients controlled in both treatment groups was compared using Fisher's exact test. Results were considered significant if $P<.05$. Data are expressed as mean \pm SEM.

\section{Results}

\section{Patient population}

Sixty-nine patients entered the study. Seventeen were withdrawn during the placebo washout for 


\begin{tabular}{|lcc|}
\hline \multicolumn{3}{|l|}{ TABLE 2. CHARACTERISTICS OF PATIENTS ENTERING TITRATION } \\
PHASE.
\end{tabular}

reasons listed in Table 1 . The remaining 52 patients entered the titration phase of the study.

The characteristics of patients entering the titration phase are listed in Table 2. They were elderly, and most were men with elevated diastolic blood pressures. Twelve percent had isolated systolic hypertension. None of the patient characteristics examined at baseline, including laboratory values, differed significantly between the two treatment groups, with the exception of the standing pulse rate, which was significantly lower in the labetalol group (Table 3 ).

\section{Titration phase}

One patient in the labetalol group withdrew from the study after one week of titration because of chest pain, which his private physician thought was not drug related but rather a repeat of previous episodes of pain.

All 25 patients treated with labetalol throughout the titration phase achieved goal blood pressures, and 14 patients did so after one week of therapy on a dosage of $100 \mathrm{mg}$ twice daily (Table 4). Therefore, none of the labetalol-treated patients required addition of HCTZ to enter the maintenance phase.

One of the placebo-treated patients dropped our during the titration phase for personal reasons. Of the remaining 25 placebo-treated patients, $12(48 \%)$ failed to attain goal blood pressure $P<.05$, compared with labetalol group) and were treated with HCTZ ( $50 \mathrm{mg} /$ daily). Four of the 12 patients taking placebo plus HCTZ failed to attain the goal reduction of blood pressure and were withdrawn from

\begin{tabular}{|c|c|c|}
\hline Parameter & Labetalol & Placebo \\
\hline Baseline & $\mathrm{N}=26$ & $\mathrm{~N}=26$ \\
\hline Systolic BP & $159.1 \pm 2.6$ & $153.9 \pm 3.2$ \\
\hline Diastolic BP & $92.4 \pm 1.2$ & $95.1 \pm 1.0$ \\
\hline Heart rate & $75.7 \pm 2.0^{*}$ & $84.8 \pm 3.1$ \\
\hline End Titration & $\mathrm{N}=25$ & $\mathrm{~N}=26$ \\
\hline Systolic BP & $136.3 \pm 2.5$ & $138.7 \pm 3.0$ \\
\hline Diastolic BP & $79.9 \pm 1.1^{*}$ & $86.6 \pm 1.5$ \\
\hline Heart rate & $68.6 \pm 1.4^{*}$ & $85.6 \pm 2.6^{\dagger}$ \\
\hline Maintenance & $\mathrm{N}=25$ & $\mathrm{~N}=21$ \\
\hline Systolic BP & $140.6 \pm 3.2$ & $139.0 \pm 3.1$ \\
\hline Diastolic BP & $82.1 \pm 1.7^{*}$ & $90.0 \pm 1.7$ \\
\hline Heart rate & $67.6 \pm 1.9^{*} \ddagger$ & $81.5 \pm 2.8$ \\
\hline \multicolumn{3}{|c|}{$\begin{array}{l}{ }^{*} P<0.05 \text {. At baseline, mean value in the labetalol group are com- } \\
\text { pared with the corresponding mean values in the placebo group; for } \\
\text { end titration and maintenance, changes in blood pressure from base- } \\
\text { line are compared between the respective groups, and heart rates are } \\
\text { compared with baseline values in each group. } \\
\dagger \mathrm{N}=25 \text {. } \\
\ddagger \mathrm{N}=23 \text {. }\end{array}$} \\
\hline
\end{tabular}

the study (Table 1).

The mean changes in standing blood pressure from baseline (Fig 1A) to the end of monotherapy (Fig 1B) in the titration phase were $-22.8 /-12.5$ $\mathrm{mm} \mathrm{Hg}$ for the labetalol-treated group and -3.1 / $-2.9 \mathrm{~mm} \mathrm{Hg}$ for the group treated with placebo alone $(P<.05$, labetalol versus placebo for both systolic and diastolic pressures). All labetalol patients and responders to placebo went directly into the maintenance phase.

The additon of HCTZ therapy to the 12 patients uncontrolled on placebo resulted in a mean change from baseline blood pressure in the group of - 15.2/ $-8.5 \mathrm{~mm} \mathrm{Hg}$ (not significant for systolic pressure and $P<.05$ for diastolic pressure, when compared with the labetalol group [Fig 1C, Table 3]).

\section{Maintenance phase}

Twenty-five labetalol-treated patients and 21 placebo-randomized patients, eight of whom were also taking HCTZ, entered the maintenance phase. One patient controlled with placebo did not make his final visit, and data from his first maintenance visit were used for calculations. Dosage adjustments were made as deemed necessary by the investigator. One patient receiving placebo required the addition of HCTZ (25 mg twice a day), and six patients receiving labetalol received an increase and one a reduction in dosage.

Slight, statistically insignificant increases in mean blood prssure values were observed in the maintenance phase. Mean pressures increased by 4.3/2.2 $\mathrm{mm} \mathrm{Hg}$ for patients receiving labetalol, and $0.3 / 3.4 \mathrm{~mm} \mathrm{Hg}$ for the patients receiving placebo 


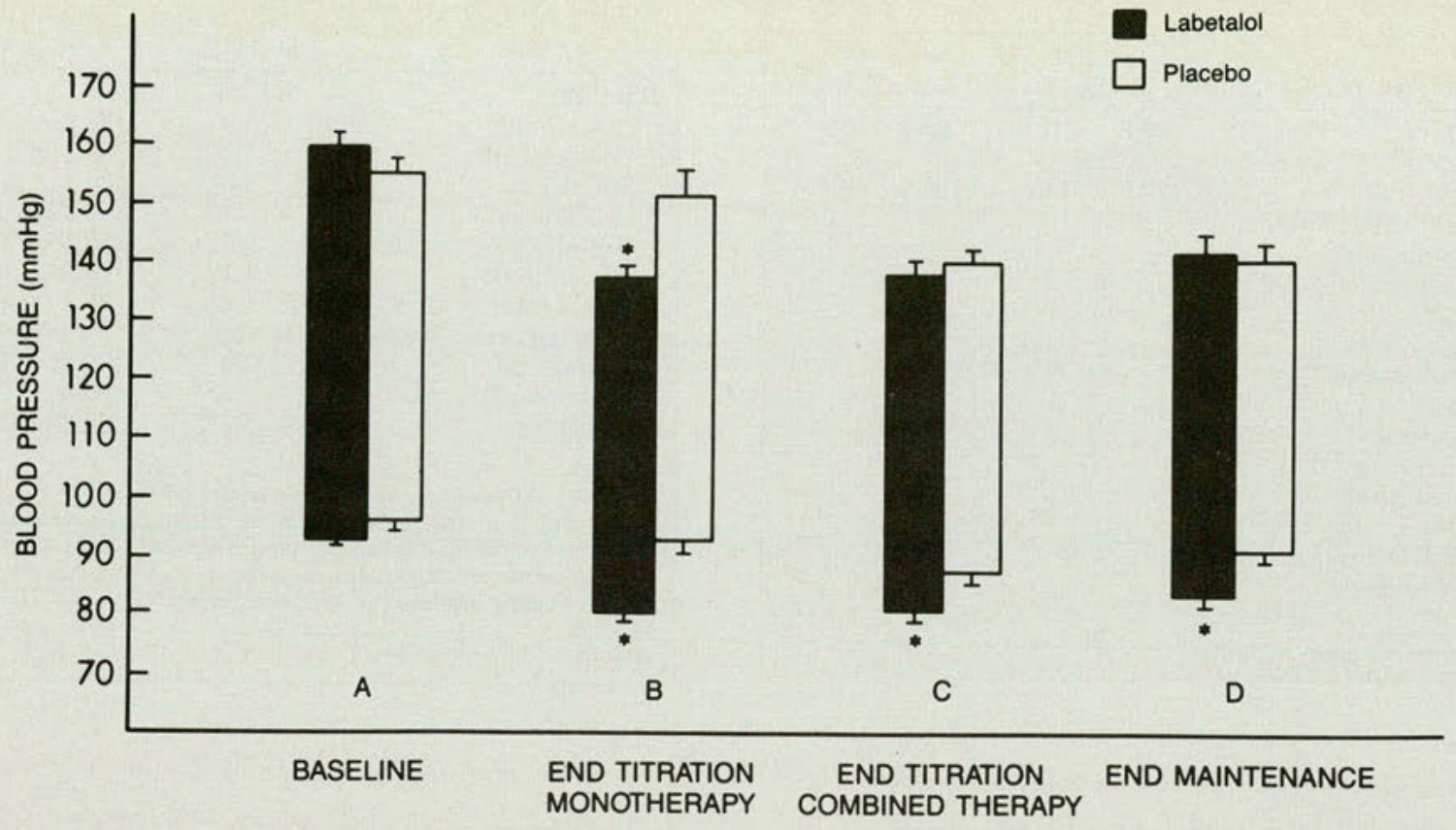

Fig 1 The tops and bottoms of the columns indicate the mean systolic and diastolic blood pressures, respectively. SEM is expressed by bars. A, Baseline values are shown. B, Monotherapy signifies labetalol versus placebo alone during initial 4 weeks of titration. $C$, End titration ( up to 8 weeks, if needed) includes patients who received labetalol, placebo, and placebo plus HCTZ. D, End maintenance refers to the last visit of the study. The asterisks at tops and bottoms of bars indicates significant differences in systolic and diastolic blood pressure, respectively, between the two groups at each phase of they study.

alone or in combination with HCTZ (Fig 1D). At the end of the maintenance phase, blood pressures were controlled in 18 of $25(72 \%)$ patients taking labetalol (Table 4), and in 10 of $21(48 \%)$ patients taking placebo (4 of 12 ) or combined placebo and HCTZ ( 6 of 9 ). Thirteen of the controlled labetalol patients were taking $<200 \mathrm{mg}$ twice daily (Table 4 ).

There was a significant decrease from baseline in standing heart rate in the labetalol group but not in the placebo group (Table 3 ).

\section{Safety considerations}

Both treatment regimens were well tolerated, and no patient in either group experienced any serious complications. All adverse events were recorded regardless of their relationship to therapy. Such events were experienced by ten of $26(38 \%)$ patients taking labetalol and seven of $26(27 \%)$ patients taking placebo or placebo and HCTZ during titration, and by nine of $25(36 \%)$ patients receiving labetalol and four of 21 (19\%) patients receiving placebo or placebo and HCTZ during maintenance.

Adverse events that the investigator considered to be drug related were reported by six patients in the labetalol group and by none in the placebo group. The most frequent complaint (three patients) was cramps or fatigue in the legs. Two patients on labetalol therapy reported orthostatic dizziness, but only one case was deemed drug related; it resolved when dosage was reduced from $400 \mathrm{mg}$ twice daily to $200 \mathrm{mg}$ twice daily. One incident each of excessive sweating, constipation, impotence, and rash, all drug related, also was reported.

Abnormal laboratory values were more prevalent in patients taking HCTZ. Eleven of 13 patients in the placebo group who received HCTZ showed an increase in serum uric acid levels, with an average elevation of $1.6 \mathrm{mg} / \mathrm{dL}$. By comparison, six of 13 patients taking placebo alone and 14 of 26 patients receiving labetalol monotherapy had such an increase, with an average elevation in each group of $0.6 \mathrm{mg} / \mathrm{dL}$. Serum potassium levels fell below $3.0 \mathrm{mEq} / \mathrm{L}$ in two patients receiving HCTZ. Calcium levels increased to upper normal limits $(>10 \mathrm{mg} / \mathrm{dL})$ in seven patients receiving HCTZ, which was significantly different from the number receiving placebo only (two) or labetalol (four) who showed similar increases. However, average increases among all of these 13 patients were slight $(0.7 \mathrm{mg} / \mathrm{dL})$. 
TABLE 4. NUMBERS OF PATIENTS ACHIEVING BLOOD PRESSURE CONTROL WITH LABETALOL.

\begin{tabular}{|c|c|c|}
\hline Dosage (Twice daily) & Titration phase & Maintenance phase* \\
\hline $100 \mathrm{mg}$ & 14 & 7 \\
\hline $200 \mathrm{mg}$ & 6 & 6 \\
\hline $300 \mathrm{mg}$ & 2 & 4 \\
\hline $400 \mathrm{mg}$ & 3 & 1 \\
\hline $\begin{array}{l}\text { Controlled no./total } \\
\text { no. }\end{array}$ & $25 / 25(100 \%)$ & $18 / 25(72 \%)$ \\
\hline \multicolumn{3}{|c|}{$\begin{array}{l}\text { *As deemed necessary by the investigators, dosage adjustments were } \\
\text { made between the first and second visits of the maintenance phase. } \\
\text { Numbers of patients indicated are those controlled at the second mainte- } \\
\text { nance visit. }\end{array}$} \\
\hline
\end{tabular}

\section{Discussion}

The results of this study indicate that monotherapy with low dosages of labetalol is effective in controlling blood pressure in elderly patients with mild hypertension. Further, this study demonstrated that labetalol was easily titrated to effective dosage levels and was well tolerated. All patients in the labetalol group achieved goal blood pressure during the titration phase without the institution of HCTZ. Most reached these therapeutic goals while receiving only $100 \mathrm{mg}$ twice daily. At the end of maintenance, 13 of $18(72 \%)$ patients controlled on labetalol therapy required $<200 \mathrm{mg}$ twice a day.

By comparison, only 13 of 25 patients receiving placebo achieved goal blood pressure during the titration phase. The difference in efficacy was significant between the two groups. The initiation of HCTZ therapy was effective in eight of the remaining 12 patients in the placebo group. On the final visit of the study, $72 \%$ (18 of 25 ) of the patients taking labetalol and $48 \%$ (10 of 21 ) taking placebo or placebo and HCTZ had blood pressures within the targeted range.

Hypertension continues to be a major public health concern, particularly in elderly people, who constitute a growing segment of our population and in whom the prevalence of hypertension is twice that of younger adults. ${ }^{1}$ Age-related alterations in physiologic function increase the likelihood of drugrelated complications. ${ }^{14}$ Thus, it is particularly important that antihypertensive therapy for the elderly patient combines efficacy with tolerability.

Increased peripheral resistance is the primary hemodynamic abnormality in the elderly hypertensive patient and, for this reason, vasodilators are promising first-line antihypertensive agents. ${ }^{15}$ Labetalol's principal hemodynamic effect is vasodilation, ${ }^{12,13,16}$ which results in a reduction in total peripheral resistance and blood pressure, regardless of age. ${ }^{17}$ An advantage of labetalol, especially in older patients, is its ability to manage blood pressure without significant changes in cardiac output. ${ }^{17}$ In general, the adverse events linked with labetalol therapy (fatigue, dizziness, headache, gastrointestinal symptoms ${ }^{11}$ ) are infrequent, mostly transient, and usually do not require drug discontinuance. Thus, labetalol is well tolerated even in long-term therapy, ${ }^{12}$ and, unlike diuretics, it is not associated with electrolyte disturbances.

Complications associated with diuretic therapy are well documented. ${ }^{18} \mathrm{~A}$ major concern in the high prevalence of hypokalemia, which occurs in patients receiving long-term diuretic therapy. ${ }^{19} \mathrm{Hy}$ pokalemia has been linked with ventricular ectopic activity. ${ }^{20,21}$ This and other risks, such as glucose intolerance, ${ }^{22}$ hyponatremia, ${ }^{23}$ hypercalcemia,${ }^{24}$ hyperuricemia,${ }^{25}$ and hyperlipidemia, ${ }^{18}$ have raised questions concerning the risk-benefit relationship of diuretic therapy, particularley in patients wieth mild hypertension. ${ }^{26}$

The results of our study confirm and extend the findings reported by Eisalo and Virta. ${ }^{27}$ Their study showed that labetalol is well tolerated by elderly hypertensives and that it is usually effective in controlling blood pressure with relatively small dosages.

\section{Conclusions}

In our study, all side effects reported for patients receiving labetalol were mild, and none caused reason for exclusion. This result likely is attributable to the attainment of therapeutic goals with low dosages. Study findings suggest that labetalol can be considered as first-stage therapy for controlling mild essential hypertension in the elderly patient.

1. Harlan WR, Hull Al, Schmouder RL, et al: High blood pressure in older Americans: The First National Health and Nutrition Examination Survey. Hypertension 1984;6:802-809.

2. Working Group on Risk and High Blood Pressure: An epidemiological approach to describing risk associated with blood pressure levels: Final report. Hypertension 1985;7:641-651.

3. Kannel WB, Wolf PA, Verter J, et al: Epidemiologic assessment of the role of blood pressure in stroke: The Framingham Study. JAMA 1970;214:301-310.

4. Kannel WB: Blood pressure and the development of cardiovascular disease in the aged, in Caird FI, Dall JLC, Kennedy RD (eds): Cardiology in old age. New York, Plenum Press, 1976, p 143.

5. Hypertension Detection and Follow-up Program Cooperative Group: Five-year findings of the Hypertension Detection and Follow-up Program: II. Mortality by race, sex, and age. JAMA 1979;242:2572-2577.

6. National Heart Foundation of Australia: Treatment of mild hypertension in the elderly: Report by the management committee. Med $J$ Aust 1981;2:398-402.

7. Amery A, Birkenhager W, Brixko P, et al: Mortality and morbidity results from the European Working Party on High Blood Pressure in the Elderly trial. Lancet $1985 ; 1: 1349-1354$.

8. Messerli FH, Sundqaard-Riise K, Venture HO, et al: Essential hypertension in the elderly: Hemodynamics, intravascular volume, plasma 
renin activity, and circulating catecholemine levels. Lancet 1983;2:983. 986.

9. Messerli FH: Hemodynamic and cardiac adaptation in essential hypertension: Consequences for therapy. J Clin Hypertens 1985;1(Mar):3 14.

10. Baum T, Sybertz EJ: Pharmacology of labetalol in experimental animals. Am J Med 1983;75(4A):15-23.

11. Wallin JD, O'Neill WM Jr: Labetalol: Current research and therapeutic status. Arch Intern Med 1983;143:485-490.

12. Lund-Johansen $P$ : Short- and long-term (six-year) hemodynamic effects of labetalol in essential hypertension. Am J Med 1983;75(4A):24 31

13. Koch G: Rationale for combined alpha-beta-adrenoteceptor blockade: Hemodynamic considerations. Acta Med Scand 1982;665(suppl):87-92.

14. Greenblatt DJ, Sellers EM, Shader RI: Drug therapy: Drug disposition in old age. $N$ Engl $J$ Med 1982;306:1081-1088.

15. Koch-Weser J, O'Malley K, O'Brien E: Drug therapy: Management of hypertension in the elderly. $N$ Engl $J$ Med 1980;302:1397-1401.

16. Buhler FR, Bolli P: Changes in cardiovascular responsiveness caused by age and high blood pressure: Implications for therapy. $J$ Cardiovasc Pharmacol 1985;(suppl):S206-215.

17. Buell JC, Plachetka JR, and Thomas M: Hemodynamic effect of labetalol in elderly and young hypertensives. $J$ Clin Pharmacol 1985;25:630.

18. Ames RP: Negative effects of diuretic drugs on metabolic risk factors for coronary heart disease: Possible alternative drug therapies. Am $J$ Cardiol 1983;51:632-638.

19. Veterans Administration Cooperative Study Group on Anithy. pertensive Agents: Effects of treatment on morbidity in hypertension: III. Influence of age, diastolic pressure and prior cardiovascular disease; further analysis of side effects Circulation 1972;45:991-1004.

20. Holland OB, Nixon JV, Kuhnert L: Diuretic-induced ventricular ectopic activity. Am J Med 1981;70:762-768.
21. Ramsay LE, Toner JM, Cameron HA: Diuretic use, serum potassium and ventricular fibrillation in patients with myocardial infarction Br J Clin Pharmacol 1984;17:605.

22. Grunfeld C, Chappell DA: Hypokalemia and diabetes mellitus. Am $J$ Med 1983;75:553-554.

23. Booker JA: Severe symptomatic hyponatremia in elderly outpatients: The role of thiazide therapy and stress. $J$ Am Geriatr Soc 1984;32:108. 113.

24. Crowe M, Wollner L, Griffiths RA: Hypercalcemia following vitamin D and thiazide therapy in the elderly. Practitioner 1984;228:312. 313.

25. Breckenridge A: Hypertension and hyperuricemia. Lancet 1966;1:1518.

26. Kaplan NM: New approaches to the therapy of mild hypertension. Am J Cardiol 1983;51:621-627.

27. Eisalo A, Virta P: Treatment of hypertension in the elderly with labetalol. Acta Med Scand 1982;665(suppl):129-133.

Supported in part by a grant-in-aid from Glaxo, Inc., Research Triangle Park, NC.

From the Department of Medicine, Veterans Administration Hospital and the University of Arizona College of Medicine, Tucson, AZ (Dr Nugent), Texas College of Osteopathic Medicine, Fort Worth, TX (Dr Bleicher), and Clinical Investigations, Glaxo, Inc, Research Triangle Park, NC (Dr Plachetka).

Reprint requests to Dr Plachetka, 5 Moore Dr, Research Triangle Park, NC 27709. 